\title{
The role of prostaglandin E2 receptors in the pathogenesis of rheumatoid arthritis
}

\author{
Jennifer M. McCoy, Joan R. Wicks, and Laurent P. Audoly
}

Pfizer Global Research and Development, Department of Inflammation and Pathology, Groton, Connecticut, USA

\begin{abstract}
Rheumatoid arthritis (RA) is a chronic inflammatory disorder leading to bone and cartilage destruction. A substantial body of evidence suggests that prostaglandin E2 (PGE2) contributes to the pathogenesis of RA, and nonsteroidal anti-inflammatory drugs, inhibitors of the synthesis of PGE2 and other prostanoids, continue to be used in the treatment of this disease. To begin to understand the mechanism by which prostaglandins modulate the pathophysiology of this disease, we examined mice lacking each of the four known PGE2 (EP) receptors after generation of collagen antibody-induced arthritis, an animal model of RA. Homozygous deletion of the EP1, EP2, or EP3 receptors did not affect the development of arthritis, whereas EP4 receptor-deficient mice showed decreased incidence and severity of disease. These animals also showed reduced inflammation as assessed by circulating IL-6 and serum amyloid A levels. Joint histopathology of $E \mathrm{P}^{-/-}$animals revealed reduced bone destruction, proteoglycan loss, and type II collagen breakdown in cartilage compared with $\mathrm{EP}^{+/+}$mice. Furthermore, liver and macrophages isolated from $\mathrm{EP} 4^{-/-}$animals produced significantly less IL-1 $\beta$ and IL- 6 than control samples. Thus, PGE2 contributes to disease progression at least in part by binding to the EP4 receptor. Antagonists of this receptor might therefore provide novel agents for the treatment of RA.
\end{abstract}

J. Clin. Invest. 110:651-658 (2002). doi:10.1172/JCI200215528.

\section{Introduction}

Rheumatoid arthritis (RA) is an inflammatory disorder that affects $1 \%$ of the adult population worldwide. RA is characterized by systemic and local inflammation resulting in cartilage and bone destruction. Nonsteroidal anti-inflammatory drugs (NSAIDs), which represent an effective therapy for treating RA, elicit their effects by inhibiting cyclooxygenase (COX) activity and blocking the downstream production of prostanoids, including prostaglandin E2 (PGE2) (1-4). Analysis of synovial fluid from patients with rheumatoid arthritis has shown increases in virtually all the prostanoids, and it has been very difficult to determine whether the beneficial effects of NSAIDs stem from the inhibition of a particular subset of these agents $(5,6)$. However, several lines of evidence suggest that at least some of the proinflammatory aspects of this disease are mediated by PGE2. Specifically, PGE2 has been associated with the edema and the erosion of cartilage and juxta-

Received for publication March 25, 2002, and accepted in revised form July 5, 2002 .

Address correspondence to: Laurent P. Audoly, Pfizer Global Research and Development, Eastern Point Road, MS 8220-2355, Groton, Connecticut 06340, USA. Phone: (860) 715-5699; Fax: (860) 715-4693; E-mail: laurent_audoly@groton.pfizer.com. Conflict of interest: No conflict of interest has been declared. Nonstandard abbreviations used: rheumatoid arthritis (RA); nonsteroidal anti-inflammatory drug (NSAID);

cyclooxygenase (COX); prostaglandin E2 (PGE2); collagen antibody-induced arthritis (CAIA); serum amyloid A (SAA); matrix metalloprotease (MMP). articular bone commonly found in RA (7-12). In an animal model of polyarthritis, neutralizing PGE2 with monoclonal antibodies reduced both the signs and levels of inflammatory markers of the disease (13).

PGE2 can act through at least four different receptors, and it is not clear which of these contribute to the pathogenesis of arthritis. These EP receptors, termed EP1-4, are G protein-coupled heptahelical proteins. Each receptor subtype has a distinct pharmacological signature based on its pharmacophore and PGE2-evoked signal transduction $(14,15)$. The EP1 receptor couples to an increase in intracellular calcium concentration. The EP2 and EP4 receptors couple to the $\mathrm{G}_{\alpha \mathrm{s}}$ protein and an increase in intracellular cAMP concentration. Several EP3 receptor variants have been identified and shown to couple to different signaling pathways, including an increase or decrease in intracellular cAMP and an increase in intracellular $\mathrm{Ca}^{2+}$ concentration.

The pharmacological probes available for studying the role of EP receptors in vivo are limited by their selectivity and pharmacokinetic properties. The four EP receptors are expressed in diverse tissues implicated in RA, such as synovium, chondrocytes, liver, and monocytic phagocytes (16-24); this makes it difficult to define the role of a receptor based solely on expression patterns. Although the association between EP receptor expression and RA has been established, the biological function of individual EP receptors in RA is complex and cannot be predicted from isolated in vitro experiments. Genetic ablation of these receptors is an alternative approach for studying their physiological functions. 
Collagen antibody-induced arthritis (CAIA) in mice shares many similarities with human RA. As demonstrated in previously published reports, affected animals develop swollen, red, and ankylosed joints (3, 25-27). The infiltration of inflammatory cells, pannus formation, chondrocyte death, proteoglycan loss, and type II collagen degradation observed in the synovial cavity bears a striking resemblance to the synovial inflammation characteristic of RA (28). Acute phase response proteins such as IL-6 and serum amyloid A (SAA) are significantly upregulated in patients with $\mathrm{RA}(29,30)$. As observed in human RA, blockade of TNF- $\alpha$ actions in CAIA results in significant improvement of the disease $(26,31)$. Furthermore, because the disease is induced by passive immunization, we are able to eliminate any contribution of B cell-mediated response to the disease, allowing us to focus on the effector phase of the response. The compatibility of CAIA with diverse murine genetic backgrounds also makes it a model of choice for evaluating the impact of targeted mutations on the development of experimental arthritis.

The availability of mice deficient in each of the EP receptors suggests a mechanism by which the roles of PGE2 and individual PGE2 receptors in the pathogenesis of arthritis can be addressed. The objective of this study was to characterize the role of EP receptors in an experimental model of RA using distinct genetically modified mouse lines deficient in each individual EP receptor. Of all the EP knockout mice tested, only EP4-/mice showed an impressive resistance to development of experimental arthritis. Clinical, histopathological, and cellular markers of the disease were significantly diminished in EP4 receptor-deficient mice compared with wild-type controls, suggesting that EP4 receptors play a key role in the pathogenesis of this disease.

\section{Methods}

Generation of genetically modified mouse strains. EP1-/-, $E P 2^{-/-}, E P 3^{-/-}$, and $E P 4^{-/-}$mice were generated as previously described (32-35). EP1 $1^{-/-}$mice were maintained on a DBA1/lacJ genetic background (generated from DBA/1lacJ embryonic stem cells). EP2 and EP3 mutations were generated in the 129 /Ola embryonic stem cell line. To maintain the mutations on the inbred 129 genetic background, chimeras were bred with $129 /$ SvEv mice. Although 129/Ola and 129/SvEv mice are estimated to be greater than $98 \%$ genetically identical, heterozygous animals were crossed to $129 / \mathrm{SvEv}$ stock for at least three generations to further decrease any genetic variation between the $129 \mathrm{~Sv} / \mathrm{Ev}$ and the EP-deficient mice. EP4 ${ }^{-/-}$mice have a high rate of perinatal lethality on the 129 and C57BL/6 genetic backgrounds. However, we have generated a recombinant inbred strain of mice from three well-characterized mouse strains (129/Ola, C57BL/6, and DBA/2) in which the majority of $\mathrm{EP}^{-/-}$mice survive the perinatal period and into adulthood. All mice used were between 8 and 10 weeks of age and weighed approximately 20 g. We did not detect any significant differences in lym- phocyte, monocyte, neutrophil, basophil, or eosinophil counts between $\mathrm{EP}^{-/-}$and $\mathrm{EP}^{+/+}$mice or between any other receptor-deficient mice and their controls. All animal protocols were performed according to approved institutional guidelines at Pfizer Global Research and Development and USDA regulations.

CAIA. Mice were treated with collagen monoclonal antibody cocktail $(10 \mathrm{mg} / \mathrm{ml}, 400 \mu \mathrm{l} /$ mouse) (Chemicon International Inc., Temecula, California, USA) by intraperitoneal injection on day 0 , followed 24 hours later by an intraperitoneal injection (100 $\mu \mathrm{l}$ per mouse) of $0.25 \mathrm{mg} / \mathrm{ml}$ LPS (E. coli 0111:B4; Chemicon International Inc., Temecula, California, USA). Starting on day 2, we recorded arthritis scores on a scale of 0-3 per paw (visual scale) and summed the four scores for each animal (possible maximum score of 12). A single-blinded observer assessed swelling, redness, and ankylosis of the joints.

Histological assessment of arthritis. Mice were euthanized by $\mathrm{CO}_{2}$ inhalation and caudal vena cava puncture. The hind paws were randomly collected by two independent experimenters, then fixed with $10 \%$ neutral buffered formalin, decalcified in Immunocal (Decal Chemical Corp., Congers, New York, USA), and embedded in paraffin. Sections $(5 \mu \mathrm{m})$ were stained with 9A4 monoclonal antibody and safranin $O$. A single-blinded observer scored the sections using a modified Mankin scale (36). The 9A4 immunohistochemistry staining correlates with cleavage of type II collagen, which is scored 0 (for normal cartilage) through 4 (for diffuse staining reflecting severe bone and cartilage damage) (37). The modified Mankin score is a comprehensive histological assessment that includes evaluations of cartilage structure, proteoglycan, synovial inflammation, hyperplasia, and cellularity. Each of these is scored on a scale of $0-4$. This scale was developed to quantify changes in articular cartilage in humans with osteoarthritis, and was modified to reflect rodent size and to include synovial inflammation. For purposes of our studies, the diagnosis of CAIA was based on the presence or absence of inflammation within the synovium. Synovial inflammation and hyperplasia were graded on a relative severity scale developed for the spectrum of lesions observed in these studies. Immunostaining was not included in the modified Mankin score but paralleled loss of staining for proteoglycans.

Serum collection and biomarker measurements. On day 10 , mice were euthanized by $\mathrm{CO}_{2}$ inhalation and caudal vena cava puncture using a $1-\mathrm{ml}$ syringe connected to a 25-gauge needle. Using a gentle vacuum, blood was collected in Microtainer serum separator tubes (Becton, Dickinson and Co., Franklin Lakes, New Jersey, USA) and then spun at $1,000 \mathrm{~g}$ for 10 minutes at $4{ }^{\circ} \mathrm{C}$. The serum fraction was collected and stored at $-20^{\circ} \mathrm{C}$ until assayed. Levels of PGE2 (Cayman Chemical Co., Ann Arbor, Michigan, USA), IL-6 (R\&D Systems Inc., Minneapolis, Minnesota, USA), murine SAA (BioSource International, Camarillo, California, USA), and type II collagen antibody (Chondrex Inc., Red- 
mond, Washington, USA) were measured by ELISA according to the manufacturer's protocol.

Exudate collection and biomarker measurements. Peritoneal macrophages were collected by removing the skin from the abdomen and injecting $8 \mathrm{ml}$ of lavage fluid (HBSS) supplemented with $0.01 \%$ ( $\mathrm{vol} / \mathrm{vol}$ ) EDTA (final concentration) into the peritoneal cavity. The solution was collected from the peritoneal cavity using a 5 - $\mathrm{ml}$ syringe attached to a 23 -gauge needle and placed in $50-\mathrm{ml}$ conical polystyrene tubes on ice. The samples were spun for 10 minutes at $300 \mathrm{~g}$ at room temperature. Lavage fluid (containing peritoneal exudate) was isolated and stored at $-20^{\circ} \mathrm{C}$ until assayed (within 1 week). IL-6 and PGE2 levels were measured as described above. Total protein content was determined by the bicinchoninic acid assay (Pierce Chemical Co., Rockford, Illinois, USA).

Isolation and treatment of peritoneal macrophages. Following peritoneal exudate collection, cells were washed twice with HBSS containing 0.01\% EDTA and twice with DMEM (1\% FBS, $1 \%$ penicillin/streptomycin). The cells were resuspended in $10 \mathrm{ml}$ DMEM and counted, and the cell concentration was diluted to $10^{6} / \mathrm{ml}$ with DMEM. Cells were plated in a 96-well plate with 100 $\mu \mathrm{l} /$ well. The plate was incubated at $37^{\circ} \mathrm{C}$ in $95 \% \mathrm{O}_{2}$ and $5 \% \mathrm{CO}_{2}$ for 1-2 hours. After incubation, the supernatant was removed from the plates by inverting the plate in a sterile tissue-culture hood. Each well was washed twice with PBS. Cell culture media was then added with or without inclusion of $1 \mu \mathrm{g} / \mathrm{ml}$ LPS (E. coli 0111:B4). Cells were then incubated for 18 hours at $37^{\circ} \mathrm{C}$ in $95 \% \mathrm{O}_{2}$ and $5 \% \mathrm{CO}_{2}$ in a humidified atmosphere. Supernatants from each well were then carefully removed and placed at $-20^{\circ} \mathrm{C}$ until analysis. IL- 6 levels were measured as described above. After collecting the supernatants, the cells were lysed by adding 200 $\mu \mathrm{l} /$ well of lysis buffer consisting of $25 \mathrm{mM}$ HEPES, $0.5 \%$ Triton X-100, $250 \mathrm{mM} \mathrm{NaCl}, 1 \mu \mathrm{g} / \mathrm{ml}$ pepstatin, 1 $\mu \mathrm{g} / \mathrm{ml}$ leupeptin, and $0.1 \mathrm{mM}$ PMSF (Sigma-Aldrich, St. Louis, Missouri, USA). Plates were incubated on ice for 30 minutes and supernatants were collected. Ten microliters of sample and $50 \mu \mathrm{l}$ of substrate $(50 \mathrm{mM}$ sodium citrate at $\mathrm{pH} 4,0.2 \%$ Triton $\mathrm{X}-100$, and $2 \mathrm{mM}$ p-Nitrophenyl N-Acetyl- $\beta$-D-Glucosaminide) were added to each well and incubated at $37^{\circ} \mathrm{C}$ for $60 \mathrm{~min}$ utes. Reactions were stopped with $100 \mu \mathrm{l}$ carbonate stop solution $\left(0.11 \mathrm{M} \mathrm{Na}_{2} \mathrm{CO}_{3}\right.$ and $0.09 \mathrm{M} \mathrm{NaHCO}_{3}$, final $\mathrm{pH} \sim 10$ ), and absorbance of wells was read at 415 $\mathrm{nm}$ to determine $\beta$-hexasiminadase activity (OD $\beta$-hex). OD $\beta$-hex (indirect correlation of cell number) was used to normalize cytokine levels. The absorbance (indirect correlation of cell number) was used to normalize cytokine levels.

Detection of EP4 $m R N A$. Livers and macrophages were harvested from normal and diseased mice on day 10 and snap frozen on dry ice. Total RNA was isolated using Maxiprep columns (Qiagen Inc., Valencia, California, USA) and stored at $-80^{\circ} \mathrm{C}$ until assayed. Absorbance at 260 and $280 \mathrm{~nm}$ was determined to esti- mate RNA levels and purity. All samples had an $\mathrm{A}_{260} / \mathrm{A}_{280}$ ratio of 1.7 or higher. EP4 mRNA was detected by RT-PCR using the following oligonucleotide sequences (38): sense, $5^{\prime}$-ggtcatcttactcatcgccacctctc- $3^{\prime}$ and antisense, $5^{\prime}$-tcccactaacctcatccaccaacag- $3^{\prime}$.

Reverse transcription was performed at $42^{\circ} \mathrm{C}$ for 60 minutes followed by $95^{\circ} \mathrm{C}$ for 10 minutes. PCR was performed at $94^{\circ} \mathrm{C}$ for 2 minutes, followed by 30 cycles at $94^{\circ} \mathrm{C}$ for 30 seconds, $65^{\circ} \mathrm{C}$ for 30 seconds, and $75^{\circ} \mathrm{C}$ for 60 seconds. Elongation was performed at $72^{\circ} \mathrm{C}$ for 2 minutes.

Quantitative determination of GAPDH and IL-1 $\beta m R N A$. GAPDH and IL-1 $\beta$ mRNA levels in liver mRNA samples isolated as described above were determined by ELISA using a Quantikine mRNA kit (R\&D Systems Inc.) according to the manufacturer's protocol.

\section{Results}

To identify the role of PGE2 and its four receptors in arthritis, we used a recently developed animal model of disease. In this model, mice are injected with a single dose of antibody directed against murine type II collagen. The severity and histopathology of CAIA are similar to collagen-induced arthritis $(3,25,26)$. The signs of the disease appear 3-4 days after the injection of antibody and reach maximum severity by day 10 ; therefore assessment (based on paw swelling/redness and ankylosis) of the disease was performed on day 10 in all cases. Unlike other models, it has been reported that CAIA can be used in virtually all mouse strains, although the extent of the response can vary among strains. To verify that this model could be used in the

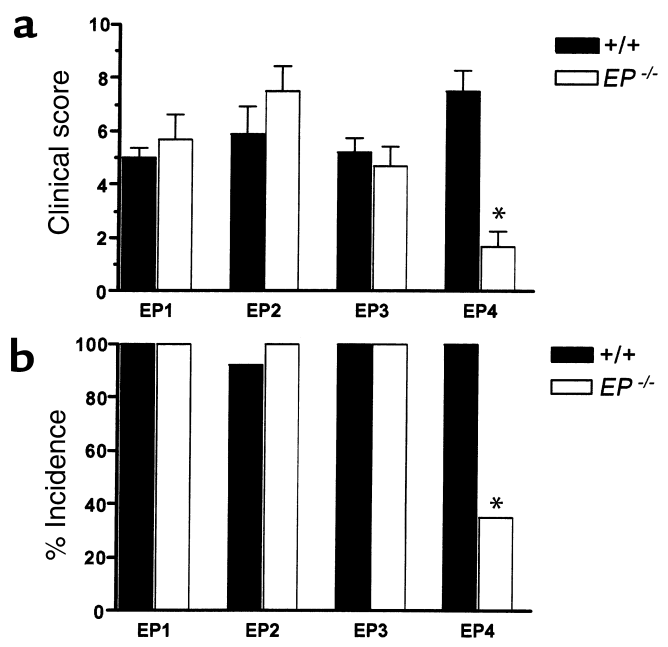

\section{Figure 1}

Development of arthritis in EP receptor-deficient animals. (a) Severity of arthritis. Mice bearing targeted mutations for each of the individual EP receptors were tested for their ability to develop clinical signs of arthritis. Paws from each mouse were scored on day 10 as described in Methods. $E P 1^{+/+}, n=7 ; E P 1^{-/-}, n=10 ; E P 2^{+/+}, n=10$; $E P 2^{-/-}, n=10 ; E P 3^{+/+}, n=8 ; E P 3^{-/-}, n=8 ; E P 4^{+/+}, n=24 ; E P 4^{-/-}$, $n=23$. ${ }^{*} P<0.05$ by Mann-Whitney $U$ test. (b) Incidence of arthritis. ${ }^{*} P<0.05$ by $\chi$-square test. 
a

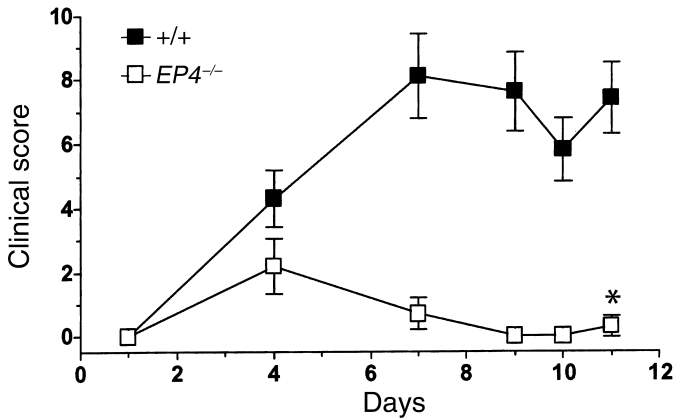

b

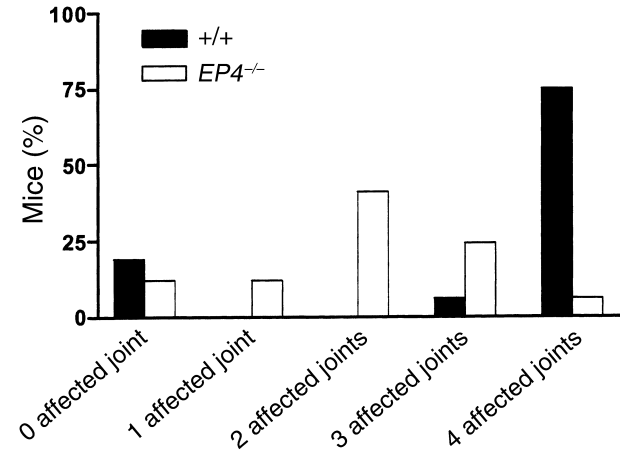

Figure 2

Time course of arthritis in EP4 receptor-deficient animals. (a) Disease progression. EP4 wild-type littermate controls and EP4-/- animals were monitored for the duration of the disease and scores were determined as previously described. An unpaired Student $t$ test was performed on the final day of the experiment $\left({ }^{*} P<0.05\right)$. (b) Distribution of affected joints. The total number of affected joints (0-4) in each animal is determined in the two genotypes. Data shown is from a representative experiment performed in triplicate.

various strains of mice in which the EP mutations were available, we first compared the incidence and severity of arthritis in DBA1/lacJ $\left(E P 1^{+/+}\right), 129\left(E P 2^{+/+}, E P 3^{+/+}\right)$, and $129 \times \mathrm{C} 57 \mathrm{BL} / 6 \times \mathrm{DBA} / 2\left(\mathrm{EP}^{+/+}\right)$wild-type animals. All four wild-type genetic controls displayed comparable histopathological signs (data not shown) and onset, severity (Figure 1a), and incidence of disease (Figure1b). Despite this similarity in the response of the various strains, we used genetically matched controls for each of the receptor-deficient mice in these studies. There was no phenotypic difference that could be attributed to the sex of the animals.

Animals deficient in EP1, EP2, or EP3 receptor compared with their genetic controls displayed no significant changes in the course of CAIA or severity of the disease on day 10 (Figure 1, a and b). There was a significant reduction in both severity and incidence of the disease in EP4 receptor-deficient animals compared with EP4 wild-type controls (Figure 1, a and b). The severity and incidence of the clinical signs of arthritis were significantly attenuated in $E P 4^{-/-}$animals compared with $E P 1$, $E P 2, E P 3$, and EP4 wild-type animals. These differences in clinical scores were detected throughout the course of the disease (Figure 2a). The eight (of 24 total) $E \mathrm{P}^{-/-}$mice that developed arthritis displayed significantly fewer severely arthritic joints than did $\mathrm{EP}^{+/+}$mice (Figure $2 \mathrm{~b}$ ).
To further quantify changes in disease, we examined the histopathological changes associated with experimental arthritis. Mice lacking EP4 receptors showed a significant reduction in Mankin (overall structure) and 9A4 (type II collagen breakdown) scores (Table 1). We observed significant structural changes in arthritic $\mathrm{EP}^{+/+}$animals (Figure 3, a, c, and e) compared with diseased $\mathrm{EP}^{-/-}$animals (Figure 3, b, d, and f). In wild-type controls, these changes included hyperplasia, loss of proteoglycan, pannus formation, and destruction of surface cartilage, as evaluated by safranin $\mathrm{O}$ staining (Figure 3 , a, and c). The integrity of the synovial cartilage in hind paws isolated from EP4 wild-type mice was evaluated by staining with the 9A4 monoclonal antibody that detects a type II collagen neoepitope (Figure 3e) (37). The appearance of this neoepitope correlates with type II collagen breakdown and suggests that $\mathrm{EP}^{-/-}$animals were protected from type II collagen degradation (Figure 3f). Stifle joints isolated from $\mathrm{EP}^{-/-}$mice presented less structural damage and type II collagen breakdown, consistent with the reduced clinical signs.

To begin to explore the possible mechanisms underlying these differences, we next evaluated the local and systemic inflammatory responses in $\mathrm{EP}^{+/+}$and $\mathrm{EP}^{-/-}$ animals. To explain the significant decrease in signs and symptoms of arthritis in the EP4 receptor-deficient animals, clinical biomarkers of disease were measured in the serum and peritoneal exudates of nondiseased and diseased animals. In wild-type unlike EP4-/mice, SAA levels were significantly elevated compared with levels in nondiseased animals (Table 2). IL-6 serum levels were increased after induction of CAIA in both $\mathrm{EP}^{+/+}$and $\mathrm{EP}^{-/-}$mice but to a significantly lesser extent in the $E P 4^{-/}$group. IL-6 and PGE2 peritoneal exudate levels followed the same pattern (Table 2). Collagen antibody levels were similar in both groups after CAIA induction, suggesting that any differences in disease outcome did not result from technical variability (Table 2). In a separate set of experiments, nondiseased $\mathrm{EP}^{+/+}$and $\mathrm{EP4^{-/- }}$ mice were injected with $25 \mu \mathrm{g}$ LPS (the same quantity used for induction of CAIA), and serum samples were collected 90 minutes later. Under these conditions, there was no detectable difference in serum IL-6 levels between the two groups (15-fold increase above baseline).

Liver and peritoneal macrophages are involved in the synthesis and release of inflammatory mediators

\section{Table 1}

Absence of EP4 receptors reduces histopathological deterioration associated with arthritis

\begin{tabular}{lcc}
\hline & $E P 4^{+/+}$ & $E P 4^{-/-}$ \\
Mankin score & $11.1 \pm 0.4(n=14)$ & $4.7 \pm 0.7^{*}(n=15)$ \\
9A4 score & $1.8 \pm 0.5(n=14)$ & $0.2 \pm 0.1^{*}(n=15)$
\end{tabular}

Mankin and 9A4 (type II collagen cleavage) scores from affected joints are presented as mean \pm SEM and were determined as described in Methods. This table summarizes histological findings (Mankin and 9A4 scores) from two independent experiments using diseased mice. ${ }^{*} P<0.05$, Mann-Whitney $U$ test. 

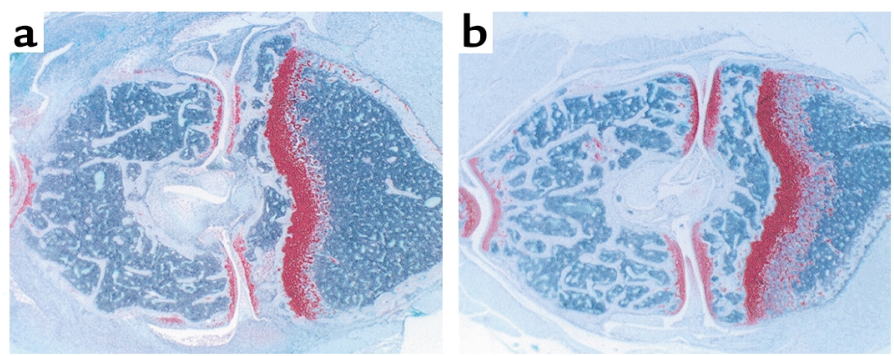

\section{Figure 3}

Targeted genetic deletion of the EP4 receptor gene protects the animals from arthritis-induced histological damage. Representative histological sections (a-d) from diseased $E P 4^{+/+}$ and $E P 4^{-/-}$mice demonstrate the significant reduction in damage as shown by safranin $\mathrm{O}$ staining (red color signifies proteoglycan presence). Wild-type mice developed severe arthritis with the formation of multiple erosions on the cartilage surface, cellular hyperplasia, and pannus formation. The articular cartilage of $E P 4^{-/-}$mice was significantly protected from disease. (a) $E P 4^{+/+}$stifle joint (2× magnification). (b) $E P 4^{-/-}$stifle joint (2× magnification). (c) Stifle joint synovial space in an $E P 4^{+/+}$animal (10× magnification). (d) Stifle joint synovial space in an EP4 ${ }^{-/-}$animal (10× magnification). (e and $\mathbf{f}$ ) Type II collagen neoepitope staining in the stifle synovial joint of $E P 4^{+/+}$and $E P 4^{-/-}$animals, respectively (20× magnification). An increase in staining $\left(E P 4^{+/+}>>\right.$ $\left.E P 4^{-/-}\right)$correlates with an increase in type II collagen breakdown $\left(E P 4^{+/+}>>P P 4^{-/-}\right)$, a hallmark of arthritis.
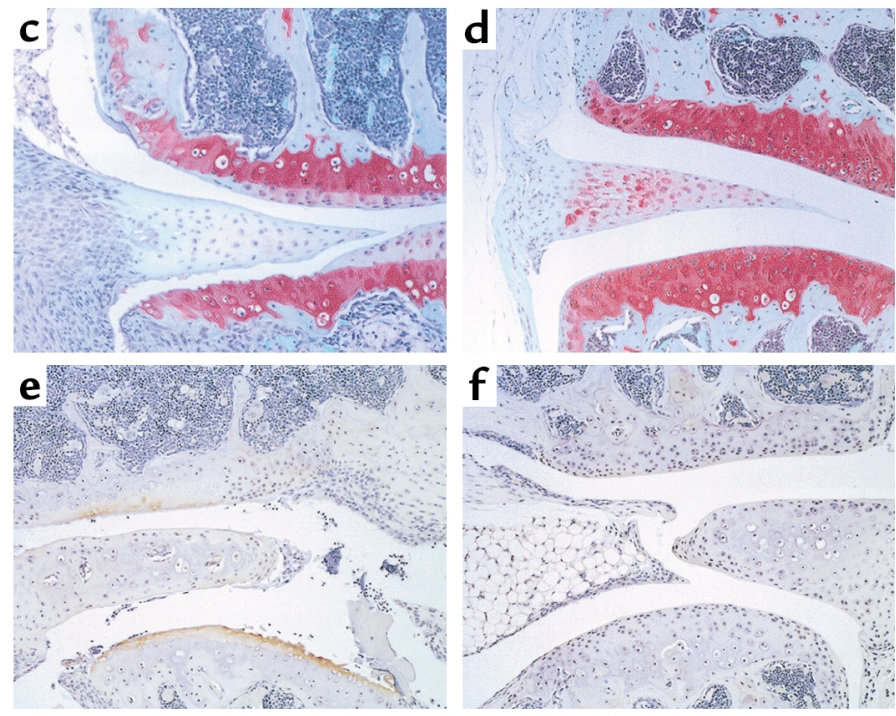

importance of the EP4 receptor in the systemic and local inflammatory responses associated with arthritis.

\section{Discussion}

Pharmacological evidence from RA trials and preclinical models of arthritis points to the importance of COX metabolites in the pathogenesis of this disease (1-3). Modulation of

such as SAA, IL-6, and PGE2. We investigated whether EP4 receptor mRNA was present in wild-type liver (Figure 4a). Our positive results suggested a role for the receptor in regulating the hepatic inflammatory response during the course of CAIA. IL- $1 \beta$ mRNA levels (normalized to GAPDH mRNA) were determined from diseased and normal $\mathrm{EP}^{+/+}$and $E P 4^{-/-}$mice (Figure $4 \mathrm{~b}$ ). There was no detectable baseline difference in IL-1 $\beta$ mRNA levels between the two groups. In contrast, levels were significantly different in diseased liver samples. These differences in inflammatory cytokine mediators were not limited to the liver. Macrophages from diseased animals were also purified and cultured overnight, and the supernatants were isolated. Wild-type macrophages expressed EP4 receptor mRNA (Figure 4c). EP4 $4^{--}$macrophages released significantly less IL-6 than did $\mathrm{EP}^{+/+}$mice under baseline conditions (Figure 4d). No difference in IL-6 levels was detected between $E P 1^{-/-}, E P 2^{-/-}$, or $E P 3^{-/-}$mice and their respective controls (data not shown). To determine the integrity of the intracellular signaling pathways, macrophages from each genotype were stimulated with $1 \mu \mathrm{g} / \mathrm{ml}$ LPS. No significant difference in IL-6 secretion was detected, demonstrating the absence of overt signaling defects (Figure $4 \mathrm{~d}$ ). These results suggest the

\section{Table 2}

Mitigation of inflammatory biomarkers in EP4 receptor-deficient animals

\begin{tabular}{lcccc} 
& \multicolumn{2}{c}{ Nondiseased } & \multicolumn{2}{c}{ Diseased } \\
& $E P 4^{+/+}$ & $E P 4^{-/-}$ & $E P 4^{+/+}$ & $E P 4^{-/-}$ \\
$\mathrm{SAA}$ & $552 \pm 138$ & $209 \pm 72$ & $3,952 \pm 1,555^{*}$ & $293 \pm 57$ \\
$(\mu \mathrm{g} / \mathrm{ml})$ & $(n=6)$ & $(n=6)$ & $(n=8)$ & $(n=8)$ \\
$\mathrm{IL}-6(\mathrm{serum})$ & $8 \pm 5$ & $8 \pm 5$ & $159 \pm 69^{*}$ & $61 \pm 25^{*}$ \\
$(\mathrm{pg} / \mathrm{ml})$ & $(n=6)$ & $(n=6)$ & $(n=8)$ & $(n=8)$ \\
$\mathrm{IL}-6($ peritoneal exudate $)$ & $1 \pm 1$ & $1 \pm 1$ & $19 \pm 6^{*}$ & $6 \pm 3$ \\
$(\mathrm{pg} / \mathrm{ml})$ & $(n=6)$ & $(n=6)$ & $(n=6)$ & $(n=6)$ \\
$\mathrm{PGE} 2($ peritoneal exudate $)$ & $803 \pm 608$ & $182 \pm 48$ & $3,346 \pm 561^{*}$ & $1,541 \pm 415$ \\
$(\mathrm{pg} / \mathrm{ml})$ & $(n=6)$ & $(n=6)$ & $(n=8)$ & $(n=8)$
\end{tabular}

Serum and peritoneal exudates were collected from $E P 4^{+/+}$and $E P 4^{-/-}$animals following CAIA These results were obtained from randomly selected animals. ${ }^{*} P<0.05$ by two-way ANOVA and Bonferroni post test. 


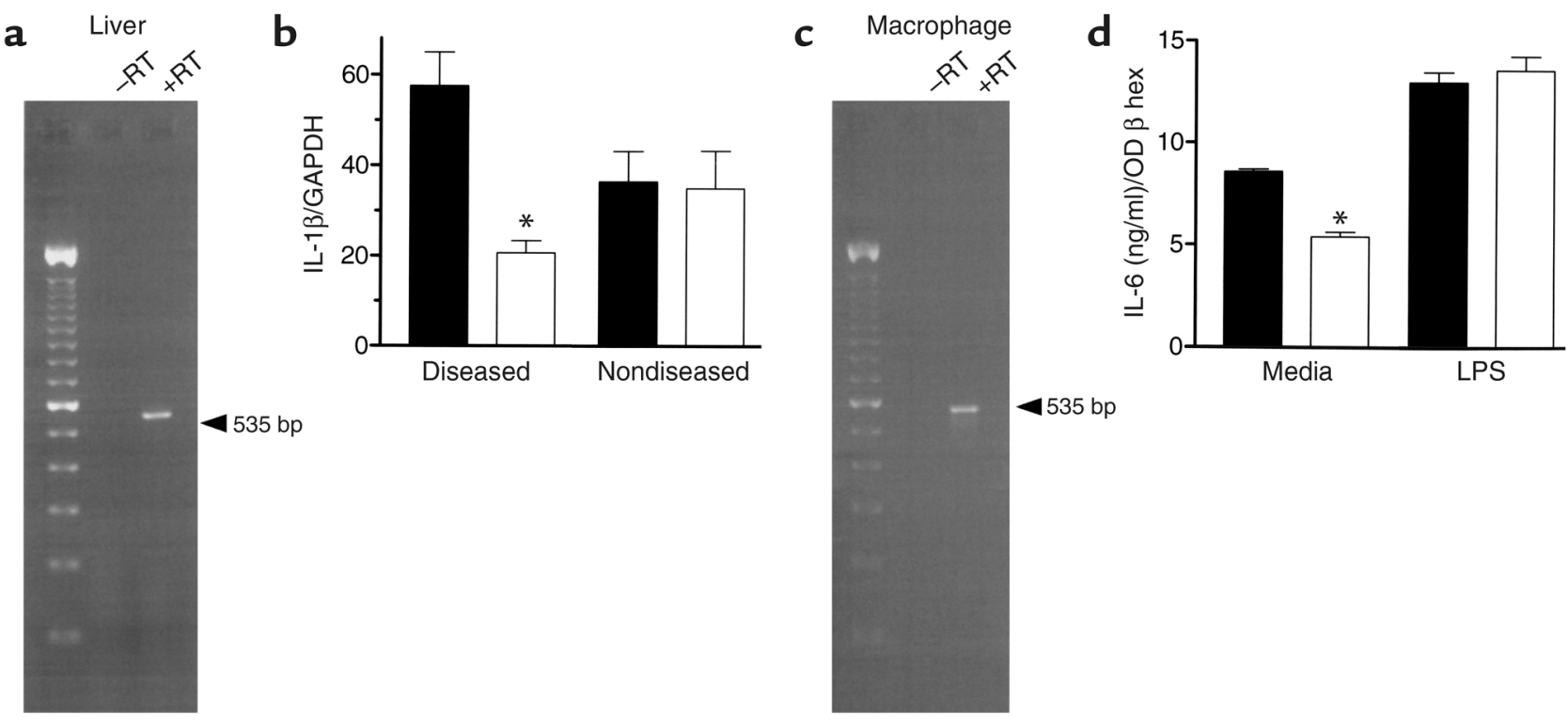

Figure 4

Role of EP4 receptors in local and systemic inflammatory responses. (a) Detection of EP4 receptor mRNA by RT-PCR in diseased EP4 ${ }^{+/+}$liver. (b) Total RNA was extracted from $E P 4^{+/+}$and $E P 4^{-/-}$normal and diseased livers, followed by IL-1 $\beta / G A P D H$ determinations as described in Methods. $E P 4^{+/+}, 36.4 \pm 6.7(n=4)$; and $E P 4^{-/}, 34.9 \pm 8.2(n=4)$, in arbitrary units (IL-1 $\beta$ pg RNA/GAPDH pg RNA). In contrast, levels were significantly different in diseased liver samples: $E P 4^{+/+}, 57.4 \pm 4.4(n=4)$ and $E P 4^{-/-}, 20.6 \pm 2.7(n=4) .{ }^{*} P<0.05$ by two-way ANOVA. (c) Detection of EP4 receptor mRNA by RT-PCR from diseased wild-type peritoneal macrophages. (d) Determination of IL-6 (ng/ml) secreted from peritoneal macrophages isolated from diseased $E P 4^{+/+}$and $E P 4^{-/-}$mice. Media only: $E P 4^{+/+}, 8.6 \pm 0.1(n=3)$; $E P 4^{-/-}, 5.4 \pm 0.1$ $(n=3)$. LPS $(1 \mu \mathrm{g} / \mathrm{ml}): E P 4^{+/+}, 12.9 \pm 0.5(n=3) ; E P 4^{-/-}, 13.5 \pm 0.7(n=3) .{ }^{*} P<0.05$, by two-way ANOVA. In $\mathbf{b}$ and $\mathbf{d}$, black bars are results from $E P 4^{+/+}$animals and white bars are results from $E P 4^{-/-}$animals. OD $\beta$ hex, $\beta$-hexasiminadase activity.

We considered several mechanisms to explain the resistance of EP4 receptor-deficient mice to developing CAIA. We examined the systemic and hepatic inflammatory responses in $\mathrm{EP}^{+/+}$and $\mathrm{EP}^{-/-}$animals. In CAIA, SAA levels in $\mathrm{EP}^{+/+}$, unlike $\mathrm{EP}^{-/-}$animals, were eightfold higher than the levels in their respective nondiseased counterparts. Both PGE2 exudate and IL-6 serum/exudate levels were significantly reduced in the diseased EP4 receptor-deficient animals compared with wild-type controls, suggesting a reduction in both local and systemic inflammation. Portanova and colleagues studied the role of PGE2 in rat antigen-induced arthritis using a PGE2-neutralizing monoclonal antibody. Animals receiving this antibody had decreased arthritis and serum IL-6 levels (13). Interestingly, several investigators have shown that IL-6-deficient mice develop significantly less arthritis than do wild-type controls (41-43). These experiments, in combination with our results, reveal an association between EP4 receptors, IL-6, and arthritis.

As described earlier, both EP2 and EP4 are coupled to $\mathrm{G}_{\alpha \mathrm{s}}$, stimulation of adenylyl cyclase, and increased concentration of intracellular cAMP. However, only EP4-mice displayed reduced CAIA, suggesting that certain properties beyond proximal signal transduction are responsible for the phenotypic difference between EP2 receptor-deficient and EP4 receptor-deficient mice. These include differences in both the pattern and level of expression of these two receptors. In general, in wild- type mice, EP4 is expressed at higher levels than is EP2 in most tissues and cells examined in our studies. While both receptors can be detected on most cell types, the relative expression of the two receptors can vary dramatically. In addition, differences have been noted in PGE2-mediated receptor desensitization and internalization between EP2 and EP4 receptors expressed in mammalian cells. EP4 receptors underwent rapid agonist-induced desensitization and internalization within 10 minutes, whereas EP2 receptors displayed no such response, even after treatment with an agonist for 30 minutes $(44,45)$. Recent studies have also highlighted the divergence of EP2 and EP4 receptors in signaling pathways located downstream of adenylyl cyclase stimulation (46). Furthermore, EP2 and EP4 receptors display different affinities for PGE2, PGE2 metabolites (e.g., 15-keto-PGE2), and synthetic analogues (e.g., butaprost free acid, 11-deoxy-PGE1), ranging from sixfold (PGE2) to greater than 200-fold (butaprost free acid) $(14,44)$. It is not surprising that EP2 receptor-deficient and EP4 receptor-deficient mice display distinct phenotypes based on the significant differences in biochemical properties and ligand binding profiles of the EP2 and EP4 receptors.

We demonstrate that genetic ablation of EP4 receptors normalizes SAA levels back to baseline, consistent with a complete reversal of the systemic and possibly hepatic inflammatory processes. The liver contributes to the inflammatory process by expressing and secret- 
ing acute-phase proteins such as SAA (47). Livers isolated from diseased animals express EP4 receptor mRNA, consistent with previously published reports. In these in vitro studies, hepatocytes, following a period of incubation with IL-6, expressed EP4 mRNA (48, 49). In vivo, IL-1 $\beta$ and IL-6 administration induce acute-phase proteins $(50,51)$. Our data show that IL-1 $\beta$ mRNA levels were significantly reduced in diseased EP4-/- livers compared with diseased wild-type controls. Collectively, our data is consistent with the participation of hepatic EP4 receptors in the acute phase response of our experimental model. However, we cannot rule out the possibility that SAA levels are indirectly related to the decrease in arthritis.

To further investigate the role of cytokines, we next examined the role of EP4 receptors on cytokine release from macrophages isolated from arthritic mice. Cytokines secreted by monocytic phagocytes are an important component of the inflammatory response in RA (52). Peritoneal macrophages freshly isolated from diseased wild-type animals express EP4 mRNA and generate significantly more IL-6 than do EP4-/peritoneal macrophages also isolated from diseased animals. This was not due to a generalized signal transduction abnormality, as demonstrated by the similar responsiveness of $\mathrm{EP}^{-/-}$and $\mathrm{EP}^{+/+}$macrophages following treatment with LPS. Our observations are consistent with published reports describing a role for EP4 receptors in cytokine release and inflammation $(21,53$, 54). Furthermore, these studies suggest that while EP4 receptor stimulation may be important in dampening extracellular TNF- $\alpha$ release, within the context of our experimental model, the reduction in IL- 6 is associated with a curtailment in inflammation.

$\mathrm{EP} 2, \mathrm{EP} 3$, and EP4 receptors are expressed in arthritic synovial cells $(16,19)$. EP4 receptor mRNA is increased during the course of synovitis in the joints of arthritic rats (16) and in synovial fibroblasts isolated from patients with RA (19). Matrix metalloproteases (MMPs) located in the synovial space (synovium and cartilage) likely contribute to cartilage degradation. Bone samples isolated from $\mathrm{EP}^{-/-}$mice express significantly less MMP2 and MMP13 than do $\mathrm{EP}^{+/+}$cells following PGE2 treatment $(55)$. Recent data $(56,57)$ suggest that MMP13 degrades type II collagen, resulting in the formation of a neoepitope detectable by the 9A4 monoclonal antibody described in our histopathological analyses. We demonstrate that type II collagen breakdown is significantly reduced in our histopathological analyses consistent with the proposed role of MMP activity.

In CAIA, genetic deletion of COX2 results in a phenotype similar to that of the $\mathrm{EP4}^{-/-}$mice (3). The majority of $\mathrm{COX} 2^{-/-}$mice showed no clinical or histological signs of arthritis. COX2 is a key enzyme involved in the metabolism of arachidonic acid to prostaglandin $\mathrm{H} 2$, which is converted to biologically active prostaglandins such as PGE2. Pharmacological inhibition of COX2 enzymatic activity in animal models of arthritis (58) and RA clinical trials leads to improved signs and symptoms of disease $(1,2)$. Our results suggest that the COX2-dependent PGE2 response in CAIA is mediated by EP4 receptors. We propose a model whereby EP4 receptors participate in both local and systemic inflammatory responses leading to the development of polyarthritis.

In summary, we characterized the role of EP receptors in an experimental model of arthritis. Targeted genetic disruption of EP1, EP2, or EP3 receptors had no impact on the development of arthritis. In contrast, EP4 receptor-deficient mice displayed little or no clinical sign of arthritis and deterioration of juxta-articular structures and bone. Inflammation biomarkers were also significantly diminished compared with $\mathrm{EP}^{+/+}$animals. Our results support the importance of both PGE2 and EP4 receptors in inflammation and suggest a novel point of pharmacological intervention in the treatment of RA.

\section{Acknowledgments}

We thank Richard Griffiths, John McNeish, Lydia Pan, and Anne Ryan for helpful discussions. The authors are grateful to Michael Derry, Linda Loverro, Jeff Stock, Tina Walsh-Spivey, and the Comparative Medicine staff of Pfizer Inc. for maintaining and breeding the genetically modified mice profiled in these experiments.

1. Bombardier, C., et al. 2000. Comparison of upper gastrointestinal toxicity of rofecoxib and naproxen in patients with rheumatoid arthritis. $N$. Engl. J. Med. 343:1520-1528.

2. Simon, L.S., et al. 1999. Anti-inflammatory and upper gastrointestinal effects of celecoxib in rheumatoid arthritis. A randomized controlled trial. JAMA. 282:1921-1928.

3. Myers, L.K., et al. 2000. The genetic ablation of cyclooxygenase 2 prevents the development of autoimmune arthritis. Arthritis Rheum. 43:2687-2693.

4. Vane, J.R. 1971. Inhibition of prostaglandin synthesis as a mechanism of action for aspirin-like drugs. Nat. New Biol. 231:232-235.

5. Egg, D. 1984. Concentrations of prostaglandins D2, E2, F2 alpha, 6-ketoF1 alpha, and thromboxane B2 in synovial fluid from patients with inflammatory joint disorders and osteoarthritis. Z. Rheumatol. 43:89-96.

6. Trang, L.E., Granstrom, E., and Lovgren, O. 1977. Levels of prostaglandin $\mathrm{F} 2 \alpha$ and $\mathrm{E} 2$ and thromboxane B2 in joint fluid in rheumatoid arthritis. Scand. J. Rheumatol. 6:151-154.

7. Davies, P., Bailey, P., Goldenberg, M., and Ford-Hutchinson, A. 1984. The role of arachidonic acid oxygenation products in pain and inflammation. Annu. Rev. Immunol. 2:335-357.

8. Griffiths, R. 1999. Prostaglandins and inflammation. In Inflammation: basic principles and clinical correlates. J. Gallin and R. Snyderman, editors. Lippincott, Williams, \& Wilkins. Philadelphia, Pennsylvania, USA. 349-360.

9. Robinson, D.R., Tashijian, A.H.J., and Levine, L. 1975. Prostaglandinstimulated bone resorption by rheumatoid synovia: a possible mechanism for bone destruction in rheumatoid arthritis. J. Clin. Invest. 56:1181-1188.

10. Dayer, J.-M., Krane, S.M., Russell, R.G.G., and Robinson, D.R. 1976. Production of collagenase and prostaglandins by a possible mechanism for bone destruction in rheumatoid arthritis. Proc. Natl. Acad. Sci. USA. 73:945-949.

11. Fulkerson, J.P., and Damiano, P. 1983. Effect of prostaglandin E2 on adult pig articular cartilage slices in culture. Clin. Orthop. 179:266-269.

12. Lippiello, L., Yamamoto, K., Robinson, D., and Mankin, H.J. 1979. Involvement of prostaglandins from rheumatoid synovium in inhibition of articular cartilage metabolism. Arthritis Rheum. 21:909-917.

13. Portanova, J.P., et al. 1996. Selective neutralization of prostaglandin E2 blocks inflammation, hyperalgesia, and interleukin 6 production in vivo. J. Exp. Med. 184:883-891.

14. Breyer, R.M., Bagdassarian, C.K., Myers, S.A., and Breyer, M.D. 2001. Prostanoid receptors: subtypes and signaling. Annu. Rev. Pharmacol. Toxicol. 41:661-690.

15. Coleman, R., Smith, W., and Narumiya, S. 1994. Pharmacological classification of prostanoid receptors: properties, distribution, and structure of receptors and their subtypes. Pharmacol. Rev. 46:205-229. 
16. Kurihara, Y., Endo, H., Akahoshi, T., and Kondo, H. 2001. Up-regulation of prostaglandin E receptor EP2 and EP4 subtypes in rat synovia tissues with adjuvant arthritis. Clin. Exp. Immunol. 123:323-330.

17. Kurihara, Y., Endo, H., and Kondo, H. 2001. Induction of IL- 6 via the EP3 subtype of prostaglandin E receptor in rat adjuvant-arthritic synovial cells. Inflamm. Res. 50:1-5.

18. Ben-Av, P., Crofford, L.J., Wilder, R.L., and Hla, T. 1995. Induction of vascular endothelial growth factor expression in synovial fibroblasts by prostaglandin $\mathrm{E}$ and interleukin-1: a potential mechanism for inflammatory angiogenesis. FEBS Lett. 372:83-87.

19. Yoshida, T., et al. 2001. Involvement of prostaglandin $E(2)$ in interleukin-1alpha-induced parathyroid hormone-related peptide production in synovial fibroblasts of patients with rheumatoid arthritis. J. Clin. Endocrinol. Metab. 86:3272-3278.

20. Faour, W.H., He, Y., and He, Q.W. 2001. Prostaglandin E(2) regulates the level and stability of cyclooxygenase- 2 mRNA through activation of p38 mitogen-activated protein kinase in interleukin-1 beta-treated human synovial fibroblasts. J. Biol. Chem. 276:31720-31731.

21. Meja, K.K., Barnes, P.J., and Giembycz, M.A. 1997. Characterization of the prostanoid receptor(s) on human blood monocytes at which prostaglandin E2 inhibits lipopolysaccharide-induced tumour necrosis factor-alpha generation. Br. J. Pharmacol. 122:149-157.

22. Katsuyama, M., et al. 1998. Characterization of the LPS-stimulated expression of EP2 and EP4 prostaglandin E receptors in mouse macrophage-like cell line, J774.1. Biochem. Biophys. Res. Commun. 251:727-731.

23. de Brum-Fernandes, A.J., Morisset, S., Bkaily, G., and Patry, C. 1996. Characterization of the PGE2 receptor subtype in bovine chondrocytes in culture. Br. J. Pharmacol. 118:1597-1604.

24. Sylvia, V.L., et al. 2001. Characterization of PGE2 receptors (EP) and their role as mediators of 1alpha,25-(OH)2D3 effects on growth zone chondrocytes. J. Steroid Biochem. Mol. Biol. 78:261-274.

25. Wallace, P.M., et al. 1999. Regulation of inflammatory responses by oncostatin M. J. Immunol. 162:5547-5555.

26. de Fourgerolles, A.R., et al. 2000. Regulation of inflammation by collagen-binding integrins $\alpha 1 \beta 1$ and $\alpha 2 \beta 1$ in models of hypersensitivity and arthritis. J. Clin. Invest. 105:721-729.

27. Terato, K., et al. 1995. Collagen-induced arthritis in mice: synergistic effect of E. coli lipopolysaccharide bypasses epitope specificity in the induction of arthritis with monoclonal antibodies to type II collagen. Autoimmunity. 22:137-147

28. Kingsley, G., and Panayi, G.S. 1997. Joint destruction in rheumatoid arthritis: biological bases. Clin. Exp. Rheumatol. 15:S3-S14.

29. Cunnane, G., et al. 2000. Serum amyloid A in the assessment of early inflammatory arthritis. J. Rheumatol. 27:58-63.

30. Hirano, T., et al. 1988. Excessive production of interleukin 6/B cell stimulatory factor-2 in rheumatoid arthritis. Eur. J. Immunol. 18:1797-1801.

31. Moreland, L.W., et al. 1997. Treatment of rheumatoid arthritis with a recombinant human tumor necrosis factor receptor ( $\mathrm{p} 75)-\mathrm{Fc}$ fusion protein. N. Engl. J. Med. 337:141-147.

32. Stock, J.L., et al. 2001. The prostaglandin E2 EP1 receptor mediates pain perception and regulates blood pressure. J. Clin. Invest. 107:325-331.

33. Tilley, S.L., et al. 1999. Reproductive failure and reduced blood pressure in mice lacking the EP2 prostaglandin E2 receptor. J. Clin. Invest. 103:1539-1545.

34. Fleming, E.F., et al. 1998. Urinary concentrating function in mice lacking EP3 receptors for prostaglandin E2. Am. J. Physiol. 275:F955-F961.

35. Nguyen, M., et al. 1997. The prostaglandin receptor EP4 triggers remodeling of the cardiovascular system at birth. Nature. 390:78-81.

36. Mankin, H., Dorfman, H., Lippiello, L., and Zarins, A. 1971. Biochemical and metabolic abnormalities in articular cartilage from osteoarthritic human hips. II. Correlation of morphology with biochemical and metabolic data. J. Bone Joint Surg. Am. 53:523-527.

37. Otterness, I., et al. 1999. Detection of collagenase-induced damage of collagen by 9A4, a monoclonal C-terminal neoepitope antibody. Matrix Biol. 18:331-341.
38. Suzawa, T., et al. 2000. The role of prostaglandin E receptor subtypes (EP1, EP2, EP3, and EP4) in bone resorption: an analysis using specific agonists for the respective EPs. Endocrinology. 141:1554-1559.

39. Zurier, R.B., and Quagliata, F. 1971. Effect of prostaglandin E1 on adjuvant arthritis. Nature. 234:304-305.

40.Zurier, R.B., Hoffstein, S., and Weissmann, G. 1973. Suppression of acute and chronic inflammation in adrenalectomized rats by pharmacological amounts of prostaglandins. Arthritis Rheum. 16:606-618.

41. Oshima, S., et al. 1998. Interleukin 6 plays a key role in the development of antigen-induced arthritis. Proc. Natl. Acad. Sci. USA. 95:8222-8226.

42. Alonzi, T., et al. 1998. Interleukin 6 is required for the development of collagen-induced arthritis. J. Exp. Med. 187:461-468.

43. de Hooge, A.S.K., van de Loo, F.A.J., Arntz, O.J., and van den Berg, W.B. 2000. Involvement of IL-6, apart from its role in immunity, in mediating a chronic response during experimental arthritis. Am. J. Pathol. 157:2081-2091.

44. Nishigaki, N., Negishi, M., and Ichikawa, A. 1996. Two Gs-coupled prostaglandin E receptor subtypes, EP2 and EP4, differ in desensitization and sensitivity to the metabolic inactivation of the agonist. Mol. Pharmacol. 50:1031-1037.

45. Desai, S., April, H., Nwaneshiudu, C., and Ashby, B. 2000. Comparison of agonist-induced internalization of the human EP2 and EP4 prostaglandin receptors: role of the carboxyl terminus in EP4 receptor sequestration. Mol. Pharmacol. 58:1279-1286.

46. Fujino, H., West, K.A., and Regan, J.W. 2002. Phosphorylation of glycogen synthase kinase- 3 and stimulation of T-cell factor signaling following activation of EP2 and EP4 prostanoid receptors by prostaglandin E2. J. Biol. Chem. 277:2614-2619.

47. Heinrich, P.C., Castell, J.V., and Andus, T. 1990. Interleukin-6 and the acute phase response. Biochem. J. 265:621-636.

48. Fennekohl, A., Schieferdecker, H.L., Jungermann, K., and Puschel, G.P. 1999. Differential expression of prostanoid receptors in hepatocytes, Kupffer cells, sinusoidal endothelial cells and stellate cells of rat liver. J. Hepatol. 30:38-47.

49. Fennekohl, A., Lucas, M., and Puschel, G.P. 2000. Induction by interleukin 6 of $\mathrm{G}(\mathrm{s})$-coupled prostaglandin $\mathrm{E}(2)$ receptors in rat hepatocytes mediating a prostaglandin $\mathrm{E}(2)$-dependent inhibition of the hepatocyte's acute phase response. Hepatology. 31:1128-1134.

50. Ramadori, G., Van Damme, J., Rieder, H., and Meyer zum Büschenfelde, K.H. 1988. Interleukin 6, the third mediator of acute-phase reaction, modulates hepatic protein synthesis in human and mouse. Comparison with interleukin 1 beta and tumor necrosis factor-alpha. Eur. J. Immunol. 18:1259-1264.

51. Neta, R., Vogel, S.N., Sipe, J.D., Wong, G.G., and Nordan, R.P. 1988. Comparison of in vivo effects of human recombinant IL1 and human recombinant IL6 in mice. Lymphokine Res. 7:403-413.

52. Kinne, R.W., Brauer, R., Stuhlmuller, B., Palombo-Kinne, E., and Burmester, G.R. 2000. Macrophages in rheumatoid arthritis. Arthritis Res. 2:189-202.

53. Sakuma, Y., et al. 2000. Impaired bone resorption by lipopolysaccharide in vivo in mice deficient in the prostaglandin E receptor EP4 subtype. Infect. Immun. 68:6819-6825.

54. Nataraj, C., et al. 2001. Receptors for prostaglandin E2 that regulate cellular immune responses in the mouse. J. Clin. Invest. 108:1229-1235. doi:10.1172/JCI200113640.

55. Miyaura, C., et al. 2000. Impaired bone resorption to prostaglandin E2 in prostaglandin E receptor EP4-knockout mice. J. Biol. Chem. 275:19819-19823.

56. Mitchell, P.G., et al. 1996. Cloning, expression, and type II collagenolytic activity of matrix metalloproteinase-13 from human osteoarthritic cartilage. J. Clin. Invest. 97:761-768.

57. Otterness, I.G., et al. 2000. Cartilage damage after intraarticular exposure to collagenase 3. Osteoarthritis Cartilage. 8:366-373.

58. Anderson, G.D., et al. 1996. Selective inhibition of cyclooxygenase (COX)-2 reverses inflammation and expression of COX-2 and interleukin 6 in rat adjuvant arthritis. J. Clin. Invest. 97:2672-2679. 